\title{
PRINCÍPIOS TEÓRICOS USADOS NA ELABORAÇÃO DE ONTOLOGIAS E SUA INFLUÊNCIA NA RECUPERAÇÃO DA INFORMAÇÃO COM USO DE INFERÊNCIAS
}

\begin{abstract}
Resumo: Diversos instrumentos da organização do conhecimento vão refletir variadas possibilidades de recuperação da informação. Nesse contexto, as ontologias possuem um potencial diferenciado pois permitem a descoberta de conhecimento, recurso que pode ser usado para recuperar informação de forma mais flexível. Entretanto, esse potencial pode ser afetado pelos princípios teóricos adotados na elaboração da ontologia. O objetivo do presente trabalho é discutir, de maneira introdutória, de que forma um conjunto (não exaustivo) de princípios teóricos pode influenciar em um aspecto das ontologias: o seu uso para obter inferências. Nesse âmbito, discute-se em especial o papel da Teoria Conceito, de Ingetraut Dahlberg. A metodologia é de natureza exploratória, qualitativa, e do ponto de vista da técnica utiliza-se de pesquisa bibliográfica apoiada pelo método de análise de conteúdo. Utiliza ainda um pequeno exemplo de aplicação a título de prova de conceito. Como resultados apresenta-se uma discussão sobre a influência da definição conceitual em inferências por subsunção, sugerem-se aportes teóricos que devem ser usados para guiar a formação de estruturas hierárquicas em que tais inferências se apoiam, e fornecem-se exemplos de como a ausência de tais aportes pode levar a inferências equivocadas.
\end{abstract}

Palavras-chave: Recuperação da informação; ontologias; inferências; teoria do conceito.

\author{
Linair Maria Campos \\ Doutora em Ciência da Informação \\ pelo convênio Universidade Federal \\ Fluminense e Instituto Brasileiro de \\ Informação em Ciência e \\ Tecnologia (UFF/IBICT). Professora \\ adjunta do Departamento de \\ Ciência da Informação e do \\ Programa de Pós-Graduação em \\ Ciência da Informação (PPGCI/UFF). \\ Imcampos@id.uff.br
}

\section{THEORETICAL PRINCIPLES USED IN ONTOLOGY BUILDING AND THEIR INFLUENCE ON INFORMATION RETRIEVAL USING INFERENCES}

\begin{abstract}
Several instruments of knowledge organization will reflect different possibilities for information retrieval. In this context, ontologies have a different potential because they allow knowledge discovery, which can be used to retrieve information in a more flexible way. However, this potential can be affected by the theoretical principles adopted in ontology building. The aim of this paper is to discuss, in an introductory way, how a (not exhaustive) set of theoretical principles can influence an aspect of ontologies: their use to obtain inferences. In this context, the role of Ingetraut Dahlberg's Theory of Concept is discussed. The methodology is exploratory, qualitative, and from the technical point of view it uses bibliographic research supported by the content analysis method. It also presents a small example of application as a proof of concept. As results, a discussion about the influence of conceptual definition on subsumption inferences is presented, theoretical contributions are suggested that should be used to guide the formation of hierarchical structures on which such inferences are supported, and examples are provided of how the absence of such contributions can lead to erroneous inferences.
\end{abstract}

Keywords: Information Retrieval; Ontologies; Inferences; Concept Theory. 


\section{INTRODUÇÃO}

Documentos, dados, recursos diversos de natureza digital, estão por toda parte. São de diferentes tipos, para diferentes públicos e propósitos, e sua quantidade, que é enorme, cresce em ritmo constante, justificando se pensar em sua organização para fins de recuperação. Ao se pensar na organização de um acervo ${ }^{1}$ de objetos informacionais, diversos aspectos devem ser considerados, como, por exemplo: (i) o que vamos organizar (o que estamos representando): se são documentos, dados ou recursos diversos tais como produtos de uma empresa para venda online e, ainda, sob que aspectos vamos considerar esse objeto no mundo; (ii) para que estamos organizando, se é para encontrar um documento, se é para descobrir conhecimento em uma base de dados, ou para responder a perguntas.

Compreender o que vamos organizar, e para que, é importante pois vai influir na forma como a sua organização deve ser realizada, de modo que se possa obter informação relevante para um usuário. Por exemplo, dados isolados não possuem um valor semântico por si só, mas podem ser articulados em um contexto para formar uma rede de significados que permita responder perguntas, podendo ainda estar associados a documentos de diversos tipos, como ocorre na Wikidata. ${ }^{2}$ Documentos podem ser organizados de acordo com suas diversas facetas, e devem ser descritos levando em conta os interesses de seus usuários e sua função social. Por exemplo, documentos arquivísticos de uma empresa costumam estar organizados por funções/atividades em uma forma de classificação funcional (SCHELLENBERG, 2006), o que facilita sua recuperação pela ação a que os documentos se referem. Livros em uma biblioteca costumam estar organizados por assuntos, em um recorte disciplinar que visa agrupá-los fisicamente por temática nas estantes.

Mas não basta compreender apenas o que vamos organizar. É necessário também refletir sobre como vamos caracterizar os objetos informacionais. Dependendo do propósito, um mesmo item pode ser encarado como um objeto único ou como uma coleção de itens. Por exemplo, do ponto de vista do arquivista organizando documentos, um processo administrativo é um único documento arquivístico, porém do ponto de vista de um analista de sistemas ele pode ser encarado como um conjunto de diversos objetos digitais que devem ser armazenados

1 Aqui considerado no sentido de um conjunto de documentos, dados ou recursos de qualquer natureza.

2 https://www.wikidata.org/wiki/Wikidata:Main_Page 
e descritos de forma individual no sistema computacional usado para tratá-los. Desse modo, é preciso um esforço para tentar compreender o objeto informacional de uma forma mais abrangente, especialmente se considerarmos que muitos deles não são estáticos e podem sofrer mudanças com o tempo, conectando-se a outros de forma dinâmica, como se observa na Wikidata, por exemplo. Segundo destaca Svenonius (2000, p 13, tradução nossa) "um documento tradicional como um livro, tende a coincidir com um objeto físico discreto. Tem claramente um início e um fim [...]. Em contraste, um documento digital, como um documento hipertextual, pode ser instável, dinâmico e sem limites identificáveis". Dessa forma, não identificar de maneira precisa o objeto, dificulta a sua organização. Conforme bem observa Svenonius (2000, p. 13, tradução nossa) “o que é difícil de identificar é difícil de descrever e, portanto, é difícil de organizar".

Seja como for, os Sistemas de Organização do Conhecimento (SOC) desempenham um papel importante para a organização desses objetos, uma vez que possuem a capacidade de destacar aspectos que podem contribuir para a sua recuperação, mediante o seu tratamento computacional por softwares voltados para esse fim. Destaca-se, nesse âmbito, a importância da precisão dessas linguagens no sentido de eliminar entendimentos ambíguos, que se por um lado são prejudicais para o entendimento humano, são ainda mais críticos do ponto de vista da máquina: "parece que o trabalho mais colossal de todos os envolvidos na organização da informação é o de ter que construir uma linguagem de descrição não ambígua" (SVENONIUS, 2000, p. 14).

Ontologias de domínio são instrumentos que podem ser usados para cumprir esse papel. Podem ser definidas do ponto de vista de um modelo conceitual como "uma especificação formal, ${ }^{3}$ explícita ${ }^{4}$ de uma conceituação compartilhada" (STUDER; BENJAMINS; FENSEL, 1998, p. 25, tradução nossa). No âmbito de um domínio, são constituídas por uma rede de elementos padronizados terminologicamente pelo consenso de um grupo de pessoas, e esses elementos podem se relacionar entre si, dependendo da conceituação que é feita. $\mathrm{Na}$ área da Ciência da Informação (CI), estudos sobre a sua elaboração se situam na área de Organização do Conhecimento, e dentre os aportes teóricos da área destaca-se a Teoria do Conceito de Ingetraut Dahlberg (1978a), que provê insumos importantes para a definição dos termos e sua estruturação em uma estrutura hierárquica. A organização da informação, enquanto processo

3 No sentido de serem legíveis por máquina.

4 No sentido de serem definidos de forma explícita. 
dentro da área de mesmo nome, está diretamente ligada ao processo de recuperação da informação, conforme Brascher e Café (2008), processo esse que se utiliza dos produtos da organização do conhecimento, os Sistemas de Organização do Conhecimento (SOC). O processo de recuperação da informação (aqui entendida no sentido de recuperação de objetos informacionais individuais) comumente se dá no âmbito de repositórios institucionais tradicionais, com buscas booleanas feitas a partir da combinação de metadados (alguns deles oriundos dos SOC usados para indexá-los) associados a esses objetos. Entretanto mecanismos de buscas mais inteligentes podem ser concebidos, a partir da exploração das relações entre os conceitos expressos nos SOC usados na indexação. Nesse contexto, ontologias são instrumentos mais adequados a esse propósito, por conta da maior riqueza semântica proporcionada pela possibilidade de suas relações e definições formais, sendo mais apropriados para o tratamento computacional com vistas a buscas semânticas, que exploram o significado formalizado para a máquina dos termos usados.

Sistemas de recuperação de informação tradicionais podem usar palavras-chave simples associadas aos documentos para a sua recuperação, ou até mesmo termos de uma taxonomia, mas sem que estejam conectados em um contexto significativo, uma "estrutura de conhecimento", que permite levar a conceitos correlatos de possível interesse (GÖDERT; HUBRICH; NAGELSCHMIDT, 2014). Além disso, quando essa estrutura de conhecimento está disponível para tratamento computacional, inferências podem ser obtidas, melhorando a qualidade da recuperação da informação. Entretanto, esse potencial pode ser afetado pelos princípios teóricos adotados na elaboração da linguagem usada para a descrição dos recursos informacionais, fazendo com que resultados equivocados, que não atendem aos interesses dos usuários, sejam obtidos com base em pressupostos errôneos, que não foram pensados para determinados objetivos. Por exemplo, uma estratégia de organização que atende muito bem a finalidade de organizar livros em uma biblioteca pode ser completamente equivocada como única opção para organizar recursos digitais quaisquer que possam ser buscados por facetas diversas, de modo a atender a diferentes necessidades informacionais de usuários com perfis distintos de interesse. Dessa forma, buscamos responder à seguinte pergunta: de que forma os aportes teóricos adotados na elaboração de ontologias podem afetar o resultado da recuperação de informação, considerando o uso de inferências? A fim de responder a este questionamento, o objetivo do presente trabalho é discutir, de maneira introdutória, de que forma um conjunto (não exaustivo) de princípios teóricos pode influenciar em um aspecto das ontologias: o seu uso 
para obter inferências. Nesse âmbito, discute-se em especial o papel da Teoria do Conceito, de Ingetraut Dahlberg.

O trabalho encontra-se estruturado em 6 seções. Na seção 2, explica-se a metodologia; na seção 3, apresenta-se conceitos básicos sobre inferências e seus usos; na seção 4 detalha-se a importância de definir o objeto de representação, tendo em vista o uso de inferências; na seção 5 apresentam-se princípios teóricos para a definição do objeto de representação, e, por fim, na seção 6 são apresentadas as conclusões.

\section{METODOLOGIA}

A metodologia adotada é de natureza exploratória, qualitativa, e do ponto de vista da técnica utiliza-se de pesquisa bibliográfica apoiada pelo método de análise de conteúdo, e de um exemplo de aplicação para fins de prova de conceito. A pesquisa bibliográfica se deu em periódicos do Portal Capes, na BRAPCI e no Google Acadêmico.

A análise de conteúdo de Bardin (2016) é composta de três etapas, denominadas de préanálise, exploração do material e tratamento dos resultados e interpretação. Cada uma dessas etapas fornece técnicas distintas que foram usadas para apoiar os procedimentos metodológicos do presente trabalho, os quais são explicados de forma resumida a seguir. A técnica da leitura flutuante foi utilizada para seleção de conteúdo a ser usado, aplicada sobre o resumo, título e palavras-chave da bibliografia recuperada mediante busca nas fontes acima relatadas. A partir daí foram escolhidos os textos a serem usados, e delimitaram-se os objetivos do trabalho. De posse dos textos a serem usados, estes foram lidos e extraídas categorias de análise que direcionaram a compreensão e sistematização dos aportes teóricos pesquisados e seu vínculo com os objetivos com vistas a atingir os resultados almejados. As categorias de análise nortearam o tratamento e interpretação dos resultados, onde se dá uma sistematização de informações e conclusões dali derivadas por reflexão fundamentada pela literatura, juntamente com os indícios obtidos em um exemplo de aplicação computacional formulado para ilustrar inferências na prática. Esse exemplo de aplicação busca ilustrar a influência dos aportes teóricos na elaboração de uma ontologia de exemplo, usada para obter inferências pelo princípio de 
subsunção. A ontologia foi desenvolvida com a ferramenta Protégé OWL ${ }^{5}$, e expressa na linguagem OWL-DL.

Está fora do escopo do presente trabalho abordar questões de desempenho e aspectos de decidibilidade da lógica usada, tampouco as diferentes possibilidades de linguagens lógicas. Procurou-se ater a inferências que podem ser realizadas com lógica descritiva, mais precisamente OWL-DL, por atender aos propósitos de exemplificar inferências e poder ser trabalhada com ferramentas largamente usadas para elaboração de ontologias, como é o caso da Protégé OWL, que possui software acoplado para realização de inferências, denominado reasoner, ou raciocinador.

\section{INFERÊNCIAS: CONCEITOS BÁSICOS E USOS NA RECUPERAÇÃO DA INFORMAÇÃO}

Antes de começarmos a tratar de inferências em ontologias, vamos estabelecer, na seção seguinte, uma terminologia básica a ser adotada no presente trabalho como um todo, de modo a não dar margem a entendimentos equivocados.

\subsection{TERMINOLOGIA BÁSICA RELACIONADA A INFERÊNCIAS EM ONTOLOGIAS}

Para entendimento dos aspectos relacionados a inferências em ontologias, julgamos importante definir os seguintes termos: entidade, conceito, conceito geral, universal, classe, indivíduo e instância de classe. Dentre estes, a noção de conceito requer uma explicação mais detalhada, pois suscita alguns contrapontos entre teóricos da área da Ontologia Formal.

Entidade, de acordo com Smith e outros (2006, p. 58, tradução nossa) é "qualquer coisa que existe, incluindo objetos, processos, qualidades e estados [...] (incluindo, assim, também representações, modelos, crenças, declarações, documentos, observações etc.)." Quando usarmos esse termo, estaremos nos referindo de uma forma mais genérica aos elementos presentes na ontologia.

Conceito, no contexto do presente trabalho é tomado na acepção de Dahlberg, em sua Teoria do Conceito, que adota uma perspectiva do realismo hipotético, na linha de G. Vollmer, Donald Campbell e Carl Popper, onde se admite que existe um mundo real que é independente

5 https://protege.stanford.edu/

PontodeAcesso, Salvador, v. 15, n. 3, p. 344-380, dez. 2021

www.pontodeacesso.ici.ufba.br 
da percepção do ser humano, é estruturado, e o que conhecemos, do ponto de vista científico, sobre esse mundo é de natureza hipotética (DAHLBERG, 1978c). Cabe destacar que Dahlberg tem uma perspectiva diferente do realismo científico de Barry Smith (SMITH; CEUSTERS, 2010), pois admite que existem várias realidades (vários mundos possíveis no que tange a definição de um referente, dependendo do ponto de vista da comunidade responsável pela conceituação do mundo $^{6}$ ), e nessa realidade se admitem também objetos que não necessariamente ocorrem na natureza (produtos da concepção intelectual do ser humano), como, por exemplo, documentos, obras de arte, e objetos da ficção (tais como unicórnios), além de objetos de natureza abstrata, como números, por exemplo: "Usando a metodologia teóricoconceitual, é possível construir sistemas conceituais relacionados a dados referentes tanto à esfera real quanto à abstrata.” (DAHLBERG, 2006, p. 13, tradução nossa). Tal entendimento é corroborado por Campos e Gomes (2014, p. 88), ao afirmar que, para Dahlberg "a expressão "unidade de conhecimento" não está relacionada com a questão da existência na realidade, e sim com um acordo firmado por um grupo de especialistas competentes em dado domínio de conhecimento.". O que de certa forma ${ }^{7}$, do ponto de vista de haver um acordo firmado, vai ao encontro de Klein e Smith (2010, p. 433, tradução nossa), que propõem que:

\footnotetext{
'Conceito' deve ser usado exclusivamente para se referir (1) ao significado de um termo geral correspondente, sendo este significado (2) único e (3) acordado pelas pessoas responsáveis no campo disciplinar determinado. Essa visão não é a posição nominalista nem conceitualista, mas é proposta aqui como uma resolução para a confusão causada pelos diferentes usos do termo [...].
}

Entretanto, acordos podem envolver diferentes perspectivas epistemológicas na percepção da realidade, conforme exemplifica Kleineberg (2014, p. 3, tradução nossa):

\footnotetext{
Claro, os elefantes existem independentemente dos observadores humanos, mas quem poderia dizer como seria um elefante em si? Mesmo um elefante não poderia dizer. O elefante em si é inqualificável, a menos que um sujeito cognoscente (não necessariamente um ser humano) o co-construa de acordo com a estrutura epistêmica subjacente deste sujeito cognoscente específico.
}

\footnotetext{
6 Por exemplo, AIDS (um só referente no mundo) pode ser classificada na Medicina experimental como doença virótica, e na Saúde Pública como doença sexualmente transmissível (GOMES, 1990).

7 Observa-se que Klein e Smith (2010) não admitem em sua ontologia entidades de ficção, apenas entidades do mundo real.
} 
Porém, Smith, no contexto de sua pesquisa das ontologias biomédicas de caráter científico, presentes na OBO Foundry, ${ }^{8}$ defende um princípio de modularidade onde se admite apenas uma ontologia, e, portanto, uma única visão de mundo para um dado domínio, que deve ser obtida pelo consenso que prevalecer na comunidade, porém com base no que se constata na realidade, do ponto de vista científico (SMITH; CEUSTERS, 2010). Dahlberg, por outro lado, atrela a definição dos conceitos a campos de conhecimento, cujo consenso é ligado a propósitos especiais (DAHLBERG, 1978b), os quais podem se traduzir em diferentes características essenciais para uma mesma entidade no mundo. Nas palavras de Gomes (2014, p. 1), que se apoiam em Dahlberg:

[...] para o desenvolvimento das taxonomias de uma organização, a característica essencial é apenas o primeiro elemento da descrição do conteúdo de um objeto e tal característica é determinada pelo público-alvo, ou, dito de outra maneira, pelos propósitos do serviço de informação. Não se pode perder de vista que ela é essencial em um dado contexto, mas pode não ser, em outro.

Dessa forma, na perspectiva de Dahlberg, admite-se a possibilidade que diferentes grupos, em domínios diferentes, venham a ter conceituações distintas sobre um mesmo referente no mundo, o que vai contra a visão de Barry Smith, de um só mundo possível. Ainda assim, tanto Smith quanto Dahlberg destacam a importância da existência do referente como base para elencar características essenciais que venham a defini-lo.

Conceito geral, a rigor, pode ser considerado em três sentidos, conforme propõe Smith e outros (2006): (i) entes da realidade que representam estruturas ou características e são exemplificados por indivíduos existentes na realidade, como, por exemplo, gato, fratura; (ii) agregado de entidades da realidade que "compartilham características comuns que não são intrínsecas às entidades em questão" (ou seja, o agregado pode reunir entidades de natureza distinta), como, por exemplo, surpresa, perigo, presente (no sentido de algo que foi presenteado); (iii) agregados, que se referem a coleções específicas de indivíduos, restritos a regiões de espaço e tempo, como, por exemplo, carioca. No presente trabalho, adota-se conceito geral no sentido (i), porém admitindo que existe mais de um mundo possível, e entidades que podem ocorrer naturalmente na natureza, entidades criadas pelo ser humano (concretas, como dinheiro, ou de ficção, como unicórnio), abstratas ou não.

Universal, é todo ente na acepção (i) dentre os três sentidos apontados por Smith e outros (2006), conforme explicado anteriormente.

8 http://www.obofoundry.org/

PontodeAcesso, Salvador, v. 15, n. 3, p. 344-380, dez. 2021

www.pontodeacesso.ici.ufba.br 
Classe, no contexto do presente trabalho, é tomada na acepção do termo por Smith e outros (2006, p. 60), como "uma coleção de todos e apenas os particulares" aos quais um determinado termo geral se aplica". Considerando que estamos usando termo geral aqui como conceito geral. Lembrando que todo universal possui uma classe correspondente, mas o contrário nem sempre se aplica (SPEAR, 2006).

Indivíduo é considerado no mesmo sentido de conceito individual, conforme Dahlberg, significando uma entidade singular, única no mundo, como, por exemplo, a Torre Eiffel (monumento situado em Paris, no Campo de Marte), e Albert Einstein (físico que formulou a Teoria da Relatividade).

Instância de classe, por fim, no contexto da ontologia enquanto artefato, é usado no sentido de indivíduo que pertence a uma classe da ontologia.

De posse do entendimento dos termos acima definidos no contexto do presente trabalho, apresenta-se a seguir a conceituação de inferência e seus usos.

\subsection{INFERÊNCIAS E SEUS USOS}

Inferências são uma forma de obter informação adicional que não está explicitada na ontologia, mas que pode ser deduzida a partir dos axiomas informados nas classes e nas afirmativas (fatos) sobre os indivíduos da ontologia, ou, nas palavras de Brachman e Levesque (2004, p. 4, tradução nossa) "Em geral, é a manipulação formal dos símbolos que representam uma coleção de proposições tidas como verdadeiras, para produzir representações de novas proposições".

Existem várias formas possíveis de inferências em ontologias (SANTAREM SEGUNDO; CONEGLIAN, 2016), sendo que a linguagem OWL-DL possui construtos que permitem a formação de uma base de conhecimento, a qual é formada por duas partes distintas, denominadas TBox (Terminological Box) e ABox (Assertional Box). A primeira contém um conjunto de classes e axiomas aplicáveis de modo geral a um dado domínio, em conformidade com uma conceituação desse domínio (conhecimento intensional) representada em classes da

9 Particular é tomado no sentido de indivíduo, conforme definição a seguir. 
ontologia, suas propriedades e axiomas que definem e/ou restringem o significado dessas classes. A segunda é utilizada para o informe de axiomas envolvendo instâncias das classes da ontologia (indivíduos) em conformidade com fatos particulares que se sabe sobre um dado cenário desse domínio (conhecimento extensional) (VIEIRA et al., 2005). Um exemplo de declaração de uma Tbox é: Animal bichinhoDe Pessoa, enquanto a contrapartida na Abox poderia ser: Lala bichinhoDe Maria (considerando Lala e Maria como indivíduos na ontologia). Existem três aspectos básicos que influenciam as inferências, que podem se dar tanto na ABox quanto na TBox: os atributos das propriedades e aspectos a elas ligados, a estrutura hierárquica das classes e os axiomas expressos tanto na definição dessas classes, quanto na representação de fatos envolvendo suas instâncias. Os reasoners usam esses aspectos não só para realizar as inferências, mas para verificar a consistência da ontologia:

OWL permite a definição de raciocinadores que são provadores automatizados de teoremas. Os raciocinadores OWL primeiro garantem que um modelo de ontologia seja consistente. Se o modelo não for consistente, o raciocinador destacará a provável origem da inconsistência. Se o modelo for consistente, os raciocinadores podem deduzir informações adicionais [...] (DUTTA; DEBELLIS, 2020, p. 4, tradução nossa).

Em relação aos atributos das propriedades, a linguagem OWL-DL permite expressar que uma propriedade pode ser: transitiva, simétrica, assimétrica, reflexiva, irreflexiva, funcional. Também existem aspectos para indicar se existe uma propriedade inversa à propriedade em questão, propriedades disjuntas, equivalentes, assim como o seu domínio (domain) e contradomínio (range) (DEBELLIS, 2021), que, grosso modo, tem a ver com a ordem das classes na formação dos axiomas e que deve ser usado com cautela pois pode levar a inferências equivocadas dependendo da disjunção ou não de classes.

O Quadro 1 ilustra alguns cenários possíveis de inferências obtidas a partir de atributos e aspectos das propriedades elencados anteriormente envolvendo axiomas e indivíduos da ontologia. Aspectos de inferências em decorrência da estrutura hierárquica da ontologia (inferência por subsunção) serão detalhados na seção 3. Entretanto, para fins de entendimento básico, entendemos que esse tipo de inferência se dá pela implicação derivada das relações de subclasse na ontologia. Em outras palavras: “A noção de que 'B é uma subclasse de A' significa 'B implica A' enfatizando o significado de subsunção” (RECTOR et al., 2004, p. 70, tradução nossa). 
Quadro 1: Cenários possíveis de inferências a partir de atributos de propriedades

\begin{tabular}{|c|c|c|c|}
\hline $\begin{array}{l}\text { Atributo/aspecto } \\
\text { da propriedade }\end{array}$ & $\begin{array}{l}\text { Exemplo de } \\
\text { propriedade }\end{array}$ & $\begin{array}{l}\text { Exemplo de uso } \\
\text { da propriedade }\end{array}$ & Inferência obtida \\
\hline Transitiva & pré-requisito de & $\begin{array}{l}\text { Cálculo I pré- } \\
\text { requisito de } \\
\text { Cálculo II; Cálculo } \\
\text { II pré-requisito de } \\
\text { Cálculo III }\end{array}$ & $\begin{array}{l}\text { Cálculo I pré- } \\
\text { requisito de } \\
\text { Cálculo III }\end{array}$ \\
\hline Simétrica & tem irmão & $\begin{array}{l}\text { João tem irmão } \\
\text { Pedro }\end{array}$ & $\begin{array}{l}\text { Pedro tem irmão } \\
\text { João }\end{array}$ \\
\hline Assimétrica & filhote de & $\begin{array}{l}\text { Lala é filhote de } \\
\text { Juju }\end{array}$ & $\begin{array}{l}\text { Juju não pode ser } \\
\text { filhote de Lala, } \\
\text { então a ontologia } \\
\text { ficará inconsistente } \\
\text { se for afirmado que } \\
\text { Juju é filhote de } \\
\text { Lala }\end{array}$ \\
\hline Reflexiva & conhece & $\begin{array}{l}\text { Pessoa conhece } \\
\text { Pessoa } \\
\text { João é instância de } \\
\text { Pessoa }\end{array}$ & $\begin{array}{l}\text { Pessoa conhece a si } \\
\text { mesma, então } \\
\text { João conhece João }\end{array}$ \\
\hline Irreflexiva & opera & $\begin{array}{l}\text { Pessoa opera } \\
\text { Pessoa }\end{array}$ & $\begin{array}{l}\text { Um indivíduo não } \\
\text { pode operar a si } \\
\text { mesmo, então a } \\
\text { ontologia ficará } \\
\text { inconsistente se for } \\
\text { afirmado que João } \\
\text { opera João }\end{array}$ \\
\hline Funcional & tem mãe & Lala tem mãe Juju & $\begin{array}{l}\text { Ninguém mais } \\
\text { pode ser mãe de } \\
\text { Lala, então a } \\
\text { ontologia ficará } \\
\text { inconsistente se for } \\
\text { afirmado que Lala } \\
\text { tem mãe Tuca } \\
\text { (assumindo que } \\
\text { Tuca e Juju sejam } \\
\text { indivíduos } \\
\text { diferentes) }\end{array}$ \\
\hline $\begin{array}{l}\text { Domínio (domain) } \\
\text { e contradomínio } \\
\text { (range) }\end{array}$ & $\begin{array}{l}\text { Propriedade } \\
\text { "bichinho de" com } \\
\text { domain Pessoa e } \\
\text { range Animal }\end{array}$ & $\begin{array}{l}\text { Lala bichinho de } \\
\text { Malu }\end{array}$ & $\begin{array}{l}\text { Lala é Animal, e } \\
\text { Malu é Pessoa }\end{array}$ \\
\hline
\end{tabular}

Fonte: elaboração da autora. 
Pode parecer trivial o que é inferido pelo reasoner, mas a máquina não pensa como o ser humano, e para tratar grandes volumes de dados o poder computacional é um diferencial que o ser humano não tem no que tange à descoberta de conhecimento. Por essa razão, tornase importante compreender os aspectos envolvidos e considerar que embora as inferências em si possam se dar em relação a fatos sobre indivíduos ou sobre as classes da ontologia, tanto uns quanto outros podem estar ligados a conteúdos informacionais que se deseja recuperar. Dessa forma, ao se descobrir conhecimento novo por meio de inferências, pode-se também ampliar a capacidade de recuperar informação associada. Para exemplificar, suponhamos que temos um sistema computacional onde se pode buscar por ementas de disciplinas, de acordo com determinados condições de busca em conformidade com os fatos estabelecidos em uma ontologia, como, por exemplo, seus pré-requisitos. Se buscarmos (conforme ilustrado no Quadro 1) pelas ementas das disciplinas que são pré-requisitos de Cálculo III, sem o uso de inferência recuperaríamos apenas a ementa de Cálculo II, quando a realidade é que deveríamos recuperar também a ementa de Cálculo I, se considerarmos que a relação pré-requisitos de é transitiva.

Nesse contexto, é fundamental não só entender o conceito e sua relação com outros para a formação dos axiomas, mas também pensar a natureza dessas relações e suas características, de modo que os reasoners sejam "alimentados" com dados que vão restringir de forma mais precisa o significado entendido da ontologia para a máquina, aproximando-o da conceituação pretendida pelo ser humano.

Na seção seguinte, vamos explorar de forma mais detalhada aspectos envolvidos em inferências por subsunção, feitas com base na estrutura hierárquica da ontologia, ilustrando a influência do entendimento do conceito e sua definição nesses casos.

\section{A DEFINIÇÃO DO OBJETO DE REPRESENTAÇÃO E SUA IMPORTÂNCIA NAS INFERENCIAS}

Em um modelo conceitual, temos elementos que se constituem em seus objetos de representação. De acordo com Campos (2004, p. 26) um objeto de representação é "a menor unidade de manipulação/representação de um dado contexto". Do ponto de vista de Dahlberg (1978b), o objeto de representação é o conceito, tal como o define em sua Teoria do Conceito, mas existem outras possibilidades, como, por exemplo, do ponto de vista de Barry Smith 
(2010), os universais, em uma perspectiva do realismo científico. ${ }^{10}$ Alternativamente, podemos formar um modelo de um domínio com base em assuntos, onde ali a unidade de conhecimento é o assunto (que pode ser formado por mais de um conceito), ou em um modelo orientado a objetos (usado na Ciência da Computação), em que a unidade de conhecimento é o objeto. Dessa forma, saber qual é a unidade de representação é importante. Por exemplo, o conceito de instância na orientação a objetos não é o mesmo conceito de instância na ontologia formal, e se usarmos a noção de instância da orientação a objetos para descrever indivíduos na ontologia, podemos vir a expressar fatos de modo equivocado. Na orientação a objetos é aceitável ter uma classe cão e cão maltês ser uma instância da classe cão, o que já não seria admissível em uma ontologia onde o objeto de representação são os universais (os quais pressupõem a existência de indivíduos como entidades únicas no mundo).

Uma vez identificado o objeto de representação, é preciso definir o que se entende por cada um deles. As definições são, do ponto de vista de Aristóteles, um meio de conhecer o que é real e concreto e mutável, desde que se observem aspectos que são essenciais, em detrimento daqueles que não são (REZENDE, 2012). No âmbito do presente trabalho estamos assumindo trabalhar com o conceito, na acepção da Teoria do Conceito de Dahlberg (1978b), como sendo o objeto do conhecimento. ${ }^{11}$

A definição de um conceito se dá pelo processo de análise conceitual, onde se estabelecem características que representam fatos conhecidos sobre um referente (DAHLBERG, 1978c) formando uma abstração ou conceituação (dentre outras possíveis) deste, de acordo com o consenso de uma comunidade. Essa conceituação fornece uma base para a elaboração de modelos, como é o caso das ontologias de domínio. Setzer (1986), no âmbito da modelagem de dados, explica o processo de abstração em três níveis, um sendo derivado do anterior. No primeiro nível está o mundo real, como entendido pelo ser humano, onde se situam as coisas e os fatos. No segundo nível, denominado descritivo, faz-se uma descrição em linguagem natural desse mundo real, como percebido, e no terceiro nível temos os modelos conceituais. Essa descrição em linguagem natural ocupa um papel de captar os aspectos de interesse do mundo real com vistas à sua formalização:

10 Existem outras perspectivas para entender os universais, como a do conceitualismo ou a do nominalismo

11 A definição do que vem a ser o conceito para Dahlberg será apresentada na seção 4.

PontodeAcesso, Salvador, v. 15, n. 3, p. 344-380, dez. 2021

www.pontodeacesso.ici.ufba.br 


\begin{abstract}
É, então, uma descrição do que interessa particularmente no mundo real e que deve ser inteligível para os atores e usuários deste cenário, sem que sejam necessárias regras formais para desenvolvê-lo. Progressivamente, temos o terceiro nível, onde estão as informações formais, o nível conceitual. Neste nível os modelos criados são chamados de modelos conceituais e se caracterizam por uma formalização e uma conceituação rigorosa e levam, normalmente, à construção de diagramas representativos (CAMPOS, 2015 , p. 11).
\end{abstract}

A formalização é importante para reduzir ambiguidades para o entendimento do ser humano, mas também para a máquina, e, dessa forma, é importante que nas ontologias seja expressa considerando o entendimento humano, mas também seu tratamento computacional.

Nesse sentido, para que uma conceituação possa ser comunicada entre pessoas, esta deve ser expressa primeiramente em linguagem natural, e depois em termos de um artefato concreto que deve ser representado em uma linguagem formal, mas esta linguagem possui limitações para representar a riqueza semântica da conceituação expressa em linguagem natural. Porém, é necessária ainda uma etapa intermediária, antes da formalização em um modelo, e é nesse contexto que se insere o compromisso ontológico, que cumpre o papel de preencher a lacuna semântica entre o que o homem identifica nas suas conceituações do mundo e o que é possível representar em uma ontologia através de uma linguagem. Ele é um acordo firmado por uma comunidade sobre o significado que esta aquiesce em reconhecer para a ontologia, tanto do ponto de vista da sua compreensão pelo homem quanto do seu tratamento pela máquina, através dos agentes de software. Isso implica em definir esse vocabulário de uma forma que venha a minimizar ambiguidades (CAMPOS, 2011, p. 39), e as ontologias são uma forma de especificar para a máquina esse compromisso, de forma intencional formando uma conceituação, que, de acordo com Guarino e Giaretta (1995) é um conjunto de regras que expressa de forma intensional uma parte da realidade, onde se busca restringir o significado desses elementos através da abstração de suas características. Cabe destacar que a ontologia que está expressa na TBox tem a preocupação de explicitar, de forma intencional, o significado pretendido dos seus conceitos, enquanto a que está expressa na ABox representa a realidade dos fatos de forma extensional.

Nesse contexto, o compromisso ontológico vem ocupar o espaço de mediação entre a ontologia enquanto conceituação, que está no plano da semântica do entendimento humano, e a ontologia enquanto artefato de software, que está no plano do processamento pela máquina. É formado por um conjunto de regras que objetiva minimizar ambiguidades ou entendimentos errôneos dos conceitos do mundo sendo representado de acordo com a conceituação humana, e 
embora seja voltado para o entendimento humano, é adequado para a conversão formal em uma linguagem que possa ser entendida pela máquina. Isso passa, naturalmente, pelo entendimento inequívoco do conceito e da formulação de definições precisas, o que é também destacado por Smith, Kumar e Bittner (2005). Os autores afirmam que "boas definições são aquelas que proporcionam avanços na comunicação e no entendimento; más definições são aquelas que causam entraves ou pelo menos falham no avanço da comunicação ou do entendimento" (SMITH; KUMAR; BITTNER, 2005, p. 4, tradução nossa). Ingetraut Dahlberg, autora seminal da área da Ciência da Informação, por sua vez, formulou uma teoria para tratar da identificação dos conceitos e suas características, fornecendo insumos para elaboração de definições lógicas, baseadas em pressupostos que são pensados para se identificar a natureza dos referentes no mundo, com base na identificação de suas características essenciais (DAHLBERG, 1978b). Ainda, de acordo com Campos e Gomes (2018, p. 363):

\begin{abstract}
As definições lógicas têm axiomas que restringem o significado pretendido de um termo, declarando as condições necessárias para seu uso. Assim, funcionam de maneira análoga às condições necessárias discutidas nas definições textuais e sua função de desambiguação também é análoga. Além disso, os axiomas possibilitam a formação de estruturas taxonômicas em ontologias e permitem que uma máquina execute funções que possibilitarão o estabelecimento automático de inferências sobre o domínio.
\end{abstract}

Dessa forma, as definições lógicas possuem um aspecto estruturante, baseando-se no princípio aristotélico de "genus proximum et differentia specifica", sustentando assim a formação de estruturas hierárquicas aderentes a esse princípio (CAMPOS; GOMES, 2017). Seppälä, Ruttenberg e Smith (2016), por sua vez, corroboram que o significado pretendido para um termo é especificado por meio de uma definição, que consiste em um conjunto de características que vão representar uma determinada parte da realidade, de acordo com o conhecimento ou crença que dela se tenha. Nesse sentido, destaca-se a importância das definições em ontologias e espera-se que definições embasadas de forma precisa minimizem inconsistências nesses instrumentos.

Mas ser inconsistente para a máquina não é o mesmo que ser inconsistente aos olhos do ser humano, pois para a máquina a inconsistência está centrada em informações conflitantes. Isso significa que é possível ter uma ontologia que expresse fatos que não correspondam à realidade como a interpretamos, e ainda assim a ontologia ser consistente. Por exemplo, em uma ontologia hipotética, podemos subordinar Café a Cafeteira por uma relação de subclasse, 
e para a máquina isso não é uma inconsistência, pois sem uma definição formal não há como a máquina concluir que essa afirmativa não corresponde à realidade (no caso, estaríamos expressando que Café é um tipo de Cafeteira). Ou seja, as inferências são feitas com base no conhecimento que é colocado na ontologia. Dessa forma, se o que expressamos na ontologia vai contra o que se esperaria na realidade, os softwares que irão lidar com a ontologia e raciocinar sobre ela vão chegar a resultados que podem não ser os desejados pelo ser humano, pois os softwares apenas são capazes de inferir com base em regras que foram estabelecidas previamente e nos fatos que estão disponíveis para processamento.

Diante do exposto, defendemos a ideia de que definições precisas devem embasar a elaboração de ontologias, e na seção seguinte vamos detalhar alguns princípios teóricos úteis nesse sentido, porém propomos agora uma reflexão prévia de como a falta de tais princípios pode afetar de fato a recuperação da informação.

Vejamos um exemplo, ilustrado na Figura 1, de uma ontologia hipotética, elaborada com o software Protégé OWL, ${ }^{12}$ onde reutilizou-se um trecho (os termos usados estão sublinhados em destaque) de uma hierarquia presente no tesauro de museus ${ }^{13}$ (FERREZ, 2016). Esse exemplo não visa criticar tal tesauro, que não foi elaborado para apoiar inferências, mas sim ilustrar que ontologias precisam do uso de aportes teóricos que estejam apoiados na identificação da natureza dos conceitos, identificando suas características de forma não conflitante.

12 https://protege.stanford.edu/

13 Os termos em destaque do tesauro de museus estão na mesma subordinação do tesauro original: cafeteira elétrica subordinado a cafeteira; coador de café subordinado a cafeteira; suporte de coador de café subordinado a coador de café. 
Figura 1: Ontologia hipotética com hierarquia não adequada a inferências

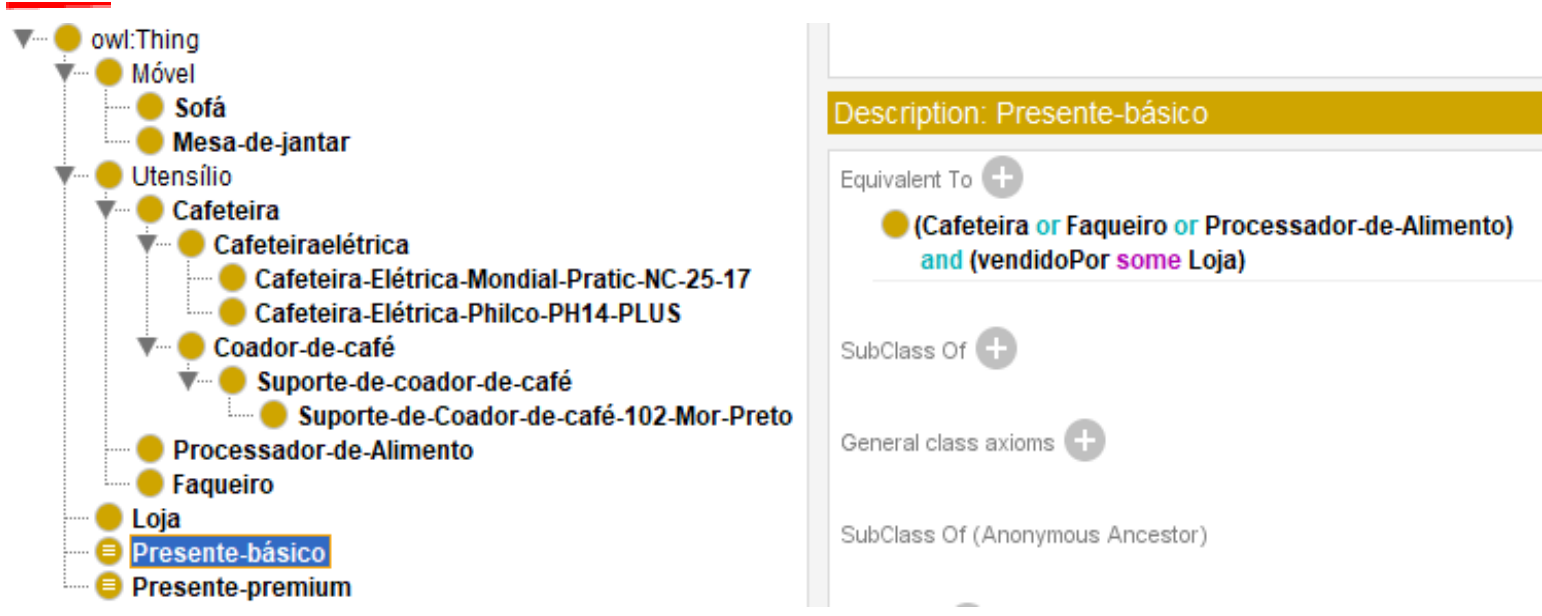

Fonte: elaboração da autora.

A fim de ilustrar o raciocínio do reasoner de modo mais claro, incluímos duas classes na ontologia que são agregados, não correspondendo a referentes da realidade: Presente-básico e Presente-premium. Essas classes são usadas aqui apenas para fins pragmáticos (representar um possível conjunto de escolhas), e não para formar hierarquias formadas pelo princípio de gênero-espécie, ${ }^{14}$ uma vez que agregam entes de diferentes naturezas. ${ }^{15}$

A ontologia ilustra um cenário onde uma pessoa procura por um presente de casamento que esteja dentro de uma das categorias propostas pelos noivos, e que esteja dentro de suas posses (o que seria a informação a ser recuperada). No caso, um presente básico, que, de acordo com o desejo dos noivos, pode ser uma cafeteira ou um faqueiro ou um processador de alimento, que seja vendido em uma loja. $\mathrm{O}$ detalhe de ser vendido em loja visa direcionar a pessoa a uma das lojas onde os noivos deixaram sua lista de presentes.

Nesse cenário, podemos conceber uma lista de possíveis produtos que podem ser adquiridos nas lojas (representados por indivíduos na ontologia), conforme ilustrado na Figura

14 Conforme aponta Svenonious (2000, p. 151) “A relação gênero-espécie é a relação lógica de inclusão. [...], é estritamente definida em termos das propriedades de reflexividade, antissimetria e transitividade. É válido entre duas classes, A e B, se e somente se todos os membros de A também forem membros de B".

15 A ontologia de fundamentação Unified Foundational Ontology (UFO) possui uma categoria para esse tipo de entidade, que agrega entes de natureza distinta, denominada Category (GUIZZARDI, 2005). 
2. Para efeitos de simplificação, estamos considerando como indivíduos não cada peça de um dado item como seria o estritamente correto (por exemplo, uma loja pode ter 100 cafeteiras de um determinado modelo), mas o item em si representando todos os itens individuais do estoque da loja.

Figura 2: preços em real dos itens disponíveis na loja $\mathrm{C}$

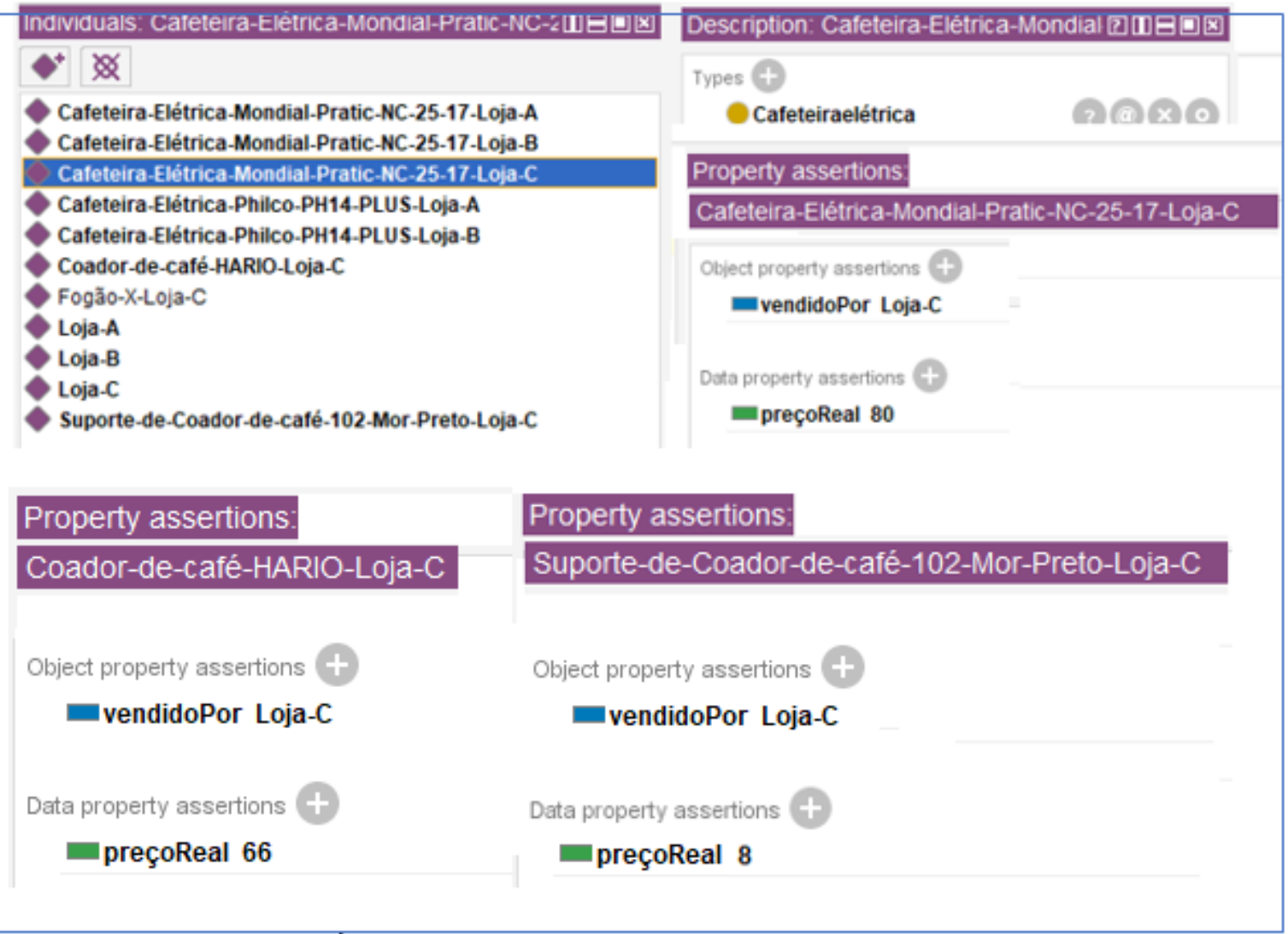

Fonte: elaboração da autora.

No cenário hipotético relatado e ilustrado na Figura 2, temos que a Cafeteira-ElétricaMondial-Pratic-NC-25-17-Loja-C custa 80 reais, o Coador-de-café-HARIO-Loja-C custa 66 reais e que o Suporte-de-Coador-de-café-102-Mor-Preto-Loja-C custa 8 reais, ambos vendidos pela Loja-C.

Ainda no mesmo cenário hipotético, a pessoa que procura por um presente básico, poderia acionar um agente de software inteligente para procurar na Loja-C o produto com o melhor preço. No ponto de vista dos noivos, esse presente básico seria, como vimos, uma cafeteria, um faqueiro ou um processador de alimento, sendo a Loja-C um dos locais indicados para a compra. Porém, os agentes "agem" de acordo com o conhecimento contido na ontologia, 
o que pode levar a resultados não desejados, conforme podemos perceber na Figura 3, onde um suporte de coador de café é inferido por subsunção como sendo um tipo de coador de café, que por sua vez é inferido por subsunção como sendo um tipo de cafeteira e, por essa razão, inferido como um presente básico. A partir daí, o reasoner aponta o indivíduo correspondente na Loja C, que vem a ser o Suporte-de-Coador-de-café-102-Mor-Preto-Loja-C.

Figura 3: Inferência justificada para suporte de coador de café como presente básico

Description: Suporte-de-Coador-de-café-102-Mor

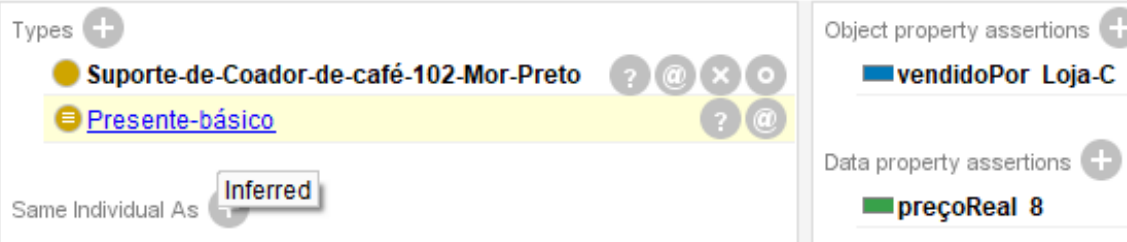

Explanation for Suporte-de-Coador-de-café-102-Mor-Preto-Loja-C Type Presente-básico

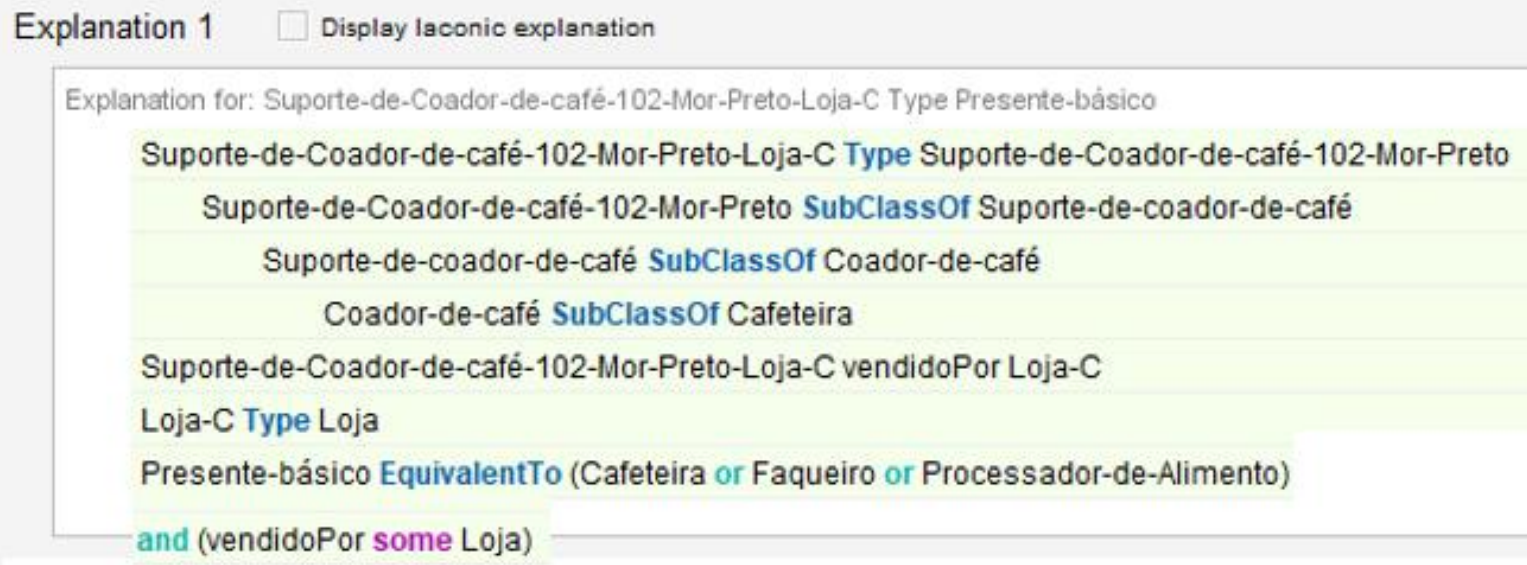

Fonte: elaboração da autora.

Para realizar a inferência utilizamos o reasoner Hermit, que vem instalado com a ferramenta Protégé versão 5.0. Essa ferramenta infere o que um agente inteligente poderia inferir. Conforme podemos perceber, o reasoner assume que o Suporte-de-Coador-de-café102-Mor-Preto-Loja-C é instância de Presente básico (indicado pelo destaque na Figura 3). E, como o preço é 8 reais, menor que o dos outros produtos inferidos (vide Figura 4), essa seria provavelmente a escolha de um agente inteligente. 
Podemos ver na Figura 3 a explicação da inferência. Como vimos, ela foi feita com base no fato que Suporte-de-Coador-de-café-102-Mor-Preto-Loja-C é instância do tipo Suporte-de-Coador-de-café-102-Mor-Preto, que por sua vez é um tipo de (subClassOf) Suporte-de-Coador-de-café, que por sua vez é um tipo de (subClassOf) Coador-de-café, que por sua vez é um tipo de (SubClassOf) Cafeteira, que é um dos itens que satisfazem a definição de Presente-básico.

Figura 4: Instâncias inferidas como sendo presentes básicos (Presente-básico)

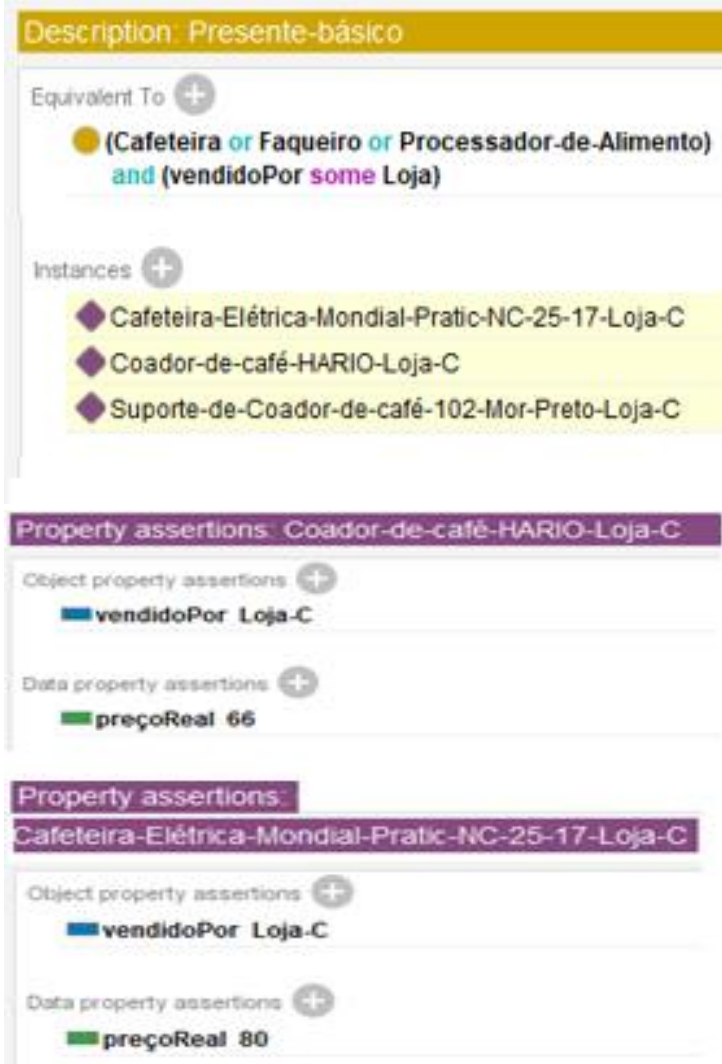

Fonte: elaboração da autora.

O que foi evidenciado no exemplo hipotético apresentado alerta para a importância de se estabelecer a natureza dos conceitos da ontologia, de modo que as hierarquias formadas estejam de acordo com características que sirvam por um lado para distinguir cada conceito dos outros, e, por outro, estabelecer o que eles possuem em comum com os de natureza semelhante.

Conforme se pode observar, os princípios usados para estruturar uma ontologia são fundamentais para os usos que dela vamos fazer e, conforme afirma Campos (2010, p. 227): "Essa organização influenciará diretamente as relações que se estabelecem entre os conceitos e, consequentemente, nas definições desses conceitos e em sua estruturação no domínio". 
Desta forma, destaca-se a importância da adoção de aportes teóricos voltados para o entendimento da natureza dos conceitos e sua definição, os quais serão abordados na seção seguinte.

\section{PRINCÍPIOS TEÓRICOS PARA A DEFINIÇÃO DO OBJETO DE REPRESENTAÇÃO E SUA APLICAÇÃO}

Conforme aponta Campos (2011), na Ciência da Computação encontramos iniciativas embasadas por pressupostos epistemológicos que descrevem as diferentes meta-propriedades dos conceitos, geralmente expressas em ontologias formais de fundamentação (GANGEMI et al., 2002; GUIZZARDI, 2005; SMITH; GRENON, 2004). O foco dessas iniciativas é a definição da natureza dos conceitos com a preocupação de que as ontologias neles fundamentadas permitam expressar modelos menos ambíguos, com uma semântica explícita de forma mais precisa, que sejam voltados para o tratamento computacional com possibilidade de inferências. Por sua vez, na Ciência da Informação, Dahlberg (1978b) com a Teoria do Conceito, fornece-nos um método de raciocínio analítico-sintético para organizar os conceitos de um domínio em grandes categorias, a partir da análise da sua definição (pensamento analítico), e da descoberta de características comuns que revelam categorias para agrupar esses conceitos (pensamento sintético). Outros aportes teóricos da Ciência da Informação também são úteis nesse contexto, como, por exemplo, a Teoria da Classificação Facetada, de Ranganathan (1967). Por questões de escopo, não vamos abordar essa contribuição no presente trabalho, porém detalhes de como essa teoria pode ser aplicada na elaboração de ontologias pode ser vista em Campos, Campos e Campos (2011).

Nas subseções seguintes vamos detalhar aspectos que são importantes para se pensar a natureza dos elementos de um domínio, abordando questões teóricas relacionadas. Para isso, na seção 5.1 apresentamos os aspectos ligados a determinar a identidade e unidade, que são usados respectivamente para se distinguir os indivíduos uns dos outros e caracterizá-los quanto à formação de um todo. Na seção 5.2 apresentamos como as definições dos conceitos podem ser usadas para compreender a identidade e unidade dos objetos de representação da ontologia. 


\subsection{DEFINIÇÃO DA IDENTIDADE E UNIDADE DE UM ENTE E SEU IMPACTO NAS ONTOLOGIAS}

Identidade diz respeito a estabelecer as características únicas que distinguem uma determinada instância (aqui considerada como um indivíduo único, particular) de uma classe das outras instâncias (GUARINO; WELTY, 2001). Unidade, por outro lado, diz respeito a estabelecer quais as partes que caracterizam uma determinada instância de uma entidade, formando um todo (possuindo uma condição de unidade), por meio de uma relação de unificação que une essas partes, e é válida para todas as instâncias dessa entidade (GUARINO; WELTY, 2001). O conceito de identidade é complementar ao de unidade, formando a noção de individualidade, ou seja: "[...] quando alguma coisa pode ser reconhecida como um todo e ao mesmo tempo se manter distinta de outros todos então dizemos que ela é um indivíduo, e pode ser contado como um" (GUARINO; WELTY, 2001, p. 1, tradução nossa). De acordo com Carrara e Vermaas (2009), a noção de identidade isola o que são objetos de um dado tipo em termos da sua essência. A questão da essência, por sua vez, está relacionada à mudança das propriedades ao longo do tempo, o que nos remete à reflexão:

Mas quais propriedades podem mudar e quais não devem? E como podemos reconhecer uma instância de uma determinada propriedade depois de algum tempo? A primeira questão leva à noção de uma propriedade essencial [...] (GUARINO; WELTY, 2001, p. 54, tradução nossa).

Lowe (2002) cita duas noções distintas, embora semelhantes, do que é uma propriedade essencial: (i) é aquela que um objeto sempre possuiu ao longo de toda a sua existência, e que não pode deixar de possuir sem deixar de existir; (ii) é aquela que um objeto sempre possuiu ao longo de sua existência e que o objeto possui em todo mundo possível em que ele existir. Ainda, de acordo com Lowe (2009, p. 21, tradução nossa), "nenhum indivíduo pode instanciar dois tipos [...] se eles têm diferentes critérios de identidade associados a eles". Cabe observar, no entanto, que determinar características essenciais que fornecem identidade nem sempre é uma tarefa fácil, e, de acordo com Kent (1978) em muitos casos é difícil de identificar e por vezes pode não existir. Ainda assim, não tem sido impeditivo para a elaboração de muitas ontologias elaboradas sob esse ponto de vista, como as da OBO Foundry. ${ }^{16}$

16 http://www.obofoundry.org/ 
Na área da CI, Dahlberg (1978a, 1978b, 1978c) também percebe a necessidade de se definir uma noção de identidade pertencente aos referentes dos conceitos, e para isso, inspirando-se em Aristóteles, lança mão das características essenciais dos conceitos, em oposição às suas características acidentais (ou possíveis), situando seu papel para a definição do conceito. Para Dahlberg, as características essenciais são necessárias para a definição do conceito enquanto as acidentais não. As características essenciais pertencem a todos os referentes de um dado tipo, enquanto as características acidentais pertencem apenas a alguns desses referentes. As características essenciais podem ser utilizadas para delimitar as condições necessárias e suficientes para definir formalmente uma classe na ontologia.

Dessa forma, o conceito de essência tem sido usado para caracterizar "o que é" um objeto através da identificação de determinadas características que sirvam para responder a essa questão, delimitando assim a sua identidade. Ao tomar a noção de identidade para formar a estrutura taxonômica da ontologia, esta estrutura forma uma árvore de classes mutuamente disjuntas de conceitos (GUARINO, 1999). Na ontologia essa estrutura é formada pela relação gens (OLIVÉ, 2007) (gênero-espécie) também denominada “is-a" ou “é-um”, indicando que o conceito subordinado herda as características do termo subordinador. Entretanto, isso nem sempre ocorre em ontologias linguísticas, que costumam representar uma relação entre palavras, e não necessariamente entre classes de conceitos de um dado domínio (GUARINO, 1999). Dessa forma, para fins de inferência, a abordagem da linguística para formação de hierarquias não é indicada. Já em contrapartida, a Teoria do Conceito de Ingetraut Dahlberg adota uma perspectiva extralinguística, de abordagem onomasiológica (CAMPOS; GOMES, 2018, p. 369) onde se busca definir o conceito a partir da identificação dos referentes "que podem se alojar em categorias - que funcionam aqui como meta-representações do domínio".

Cabe destacar que a disjunção das classes das ontologias deve ser explicitada, pois em determinadas linguagens, como é o caso da OWL, as classes são consideradas não disjuntas por padrão (da mesma forma que as propriedades). Nesse contexto, entender o que o conceito "não é" pode ajudar. Dahlberg também oferece insumos para esse entendimento, ao tratar das relações de oposição, como a de contradição, a exemplo de numérico em oposição a não numérico; contrariedade (polo-norte em oposição a polo-sul); dualidade (asa no pássaro em oposição ao braço do ser humano) e a Positiva-Indiferente-Negativa (PIN), a exemplo de favorável, neutro e desfavorável (opondo-se uns em relação aos outros) (DAHLBERG, 1992). 
Nesse âmbito, Guarino, por sua vez, observa que condições de identidade ou unidade incompatíveis apontam para conceitos disjuntos (GUARINO, 1999; GUARINO; WELTY, 2001). É o que podemos constatar no exemplo hipotético da cafeteira em relação ao coador de café. Podemos intuir que as condições de identidade e unidade de uma cafeteira não são as mesmas de um coador. Dessa forma, não poderíamos formar uma hierarquia (pelo princípio de gênero-espécie) onde um desses conceitos estivesse subordinado ao outro. Mas para saber ao certo, e não apenas intuir, é preciso se basear em uma definição do conceito. Para Dahlberg (1978b), a definição de um conceito é feita a partir do enunciado de afirmativas verdadeiras (verificáveis) sobre um referente no mundo (envolvendo outros conceitos), que são designadas por um termo, para fins de comunicação. Essas afirmativas ou predicados se constituem nas características do conceito, e são fruto de um entendimento consensual de uma comunidade sobre o que esse referente significa, em uma visão objetiva da realidade, embora sob o ponto de vista dessa comunidade, formando uma abstração, uma visão contextualizada e simplificada sobre esse referente. Como expressa um consenso sobre o conhecimento dessa comunidade, esse conceito assim definido é denominado como "unidade de conhecimento", implicando que não se trata de uma visão subjetiva, refletindo uma percepção individual, como poderia dar a entender, se fosse denominado de "unidade de pensamento" (DAHLBERG, 1978c).

Cabe destacar que, na perspectiva de Dahlberg (1978c, p. 11-12, tradução nossa), os referentes podem ser objetos do mundo real ou do pensamento, definidos em termos de afirmativas verdadeiras, ou, nas palavras da autora: "coleções de tais declarações ou elementos de conhecimento referentes a um objeto de realidade ou um objeto de pensamento verificável podem ser denominadas uma unidade de conhecimento". Observa-se, ainda que essa visão consensual da realidade reflete a compreensão que se tem do conhecimento científico em um dado momento, ou seja, admite-se que o conhecimento é hipotético. Além disso, os referentes podem ser itens individuais: uma determinada pessoa, como a autora desse artigo, um determinado evento, como o Rock in Rio ocorrido no Rio de Janeiro em 2017 etc.; ou itens gerais, como pessoas, eventos, e assim por diante.

De acordo com Dahlberg (1978c) elaboramos definições para os itens de referência gerais, não para os individuais. Quando elaboramos afirmativas sobre itens individuais estamos apenas descrevendo esse item e não conceituando-o: "Se o item de referência é algo individual [...] então as afirmações sobre este item são descrições dele [...], mas não é o próprio conceito [...]" (DAHLBERG, 1978c, p. 14, tradução nossa). Por outro lado, de acordo com a autora, 
quando um conceito geral é envolvido, então as sentenças sobre o referente vão formar suas definições.

Como vimos, as características dos conceitos podem ser acidentais ou essenciais. As características essenciais são necessárias (e suficientes) para definir o conceito enquanto um gênero (tipo), enquanto as acidentais são adicionadas para se definir os conceitos específicos em relação ao tipo, sendo que os conceitos específicos herdam as características essenciais do tipo. Por exemplo, podemos, de forma simplificada, definir que árvore é um vegetal que possui raiz e caule, características que todas as árvores possuem, enquanto árvore frutífera é um vegetal que possui raiz, caule e fruto. Dessa forma, possuir fruto é uma característica acidental de árvore, pois apenas algumas possuem fruto. Essa diferenciação permite estabelecer hierarquias de gênero e espécie, de modo que "um gênero é uma classe mais ampla composta por duas ou mais espécies diferentes, mas que têm em comum a mesma essência genérica ou natureza" (JOSEPH, 2008, p. 43), sendo que a essência é o que determina o que o ente é de fato, e o que o distingue dos demais, em conformidade com a visão aristotélica clássica. Nessa perspectiva, de acordo com Seppälä e outros (2016, p. 6, tradução nossa) temos uma relação “is-a”, ou "tipo de" implícita entre o gênero e a espécie, onde a diferença específica pode "expressar qualquer tipo de relação relevante para descrever e distinguir os tipos de coisas às quais o termo definido se refere" porém acrescentam ainda que "para trabalhar em contextos científicos e computacionais, os conteúdos relevantes devem constituir uma declaração de condições necessárias e, sempre que possível, suficientes" (SEPPÄLÄ et al., 2016, p. 6, tradução nossa). Essa divisão de um gênero em suas espécies é denominada de divisão lógica (JOSEPH, 2008), onde as espécies formam a extensão do conceito.

Dahlberg (1978b) observa que a extensão pode ser pensada também como os conceitos individuais que estejam em conformidade com o conceito que determina o gênero. Por exemplo, para o conceito cão, a extensão do ponto de vista dos conceitos específicos seria cão maltês, cão pequinês etc., enquanto do ponto de vista dos conceitos individuais seria o meu cão Bob, o cão Rex de meu amigo João, e assim por diante. Existem outros tipos de divisão possíveis, dentre as quais destacamos a divisão metafísica, que distingue a substância ${ }^{17}$ (na terminologia

17 Substância é definida, de forma simplificada, como "o indivíduo concreto, o ente ou coisa - aquilo que é "um e separado". Em segundo lugar [...] a substância passa a ser identificada à forma [...] que permite enunciar "isto que a coisa é". A substância também significa o gênero ou espécie a que pertence um indivíduo concreto. Neste caso, Aristóteles a chama de substância segunda.” (REZENDE, 2012, p. 85). 
aristotélica) de seus acidentes, podendo ser ilustrada como um conceito geral, como uma laranja (substância) sendo distinta de suas características acidentais, tais como sua cor, tamanho, doçura, perfume, e estes distintos entre si (JOSEPH, 2008). Esse entendimento é importante pois permite evidenciar uma diferença de princípios para a formação de hierarquias. Se por um lado podemos dividir uma hierarquia de forma lógica, distinguindo diferentes tipos de coisas de acordo com suas características essenciais distintas, por outro podemos formar hierarquias com base na divisão metafísica, de acordo com suas características acidentais. Por exemplo, podemos dividir logicamente cães em cão maltes, cão pequinês, cão dálmata e assim por diante. São diferentes espécies (tipos) de cão, que possuem características essenciais próprias que nos permite diferenciá-los como sendo espécies diferentes, embora do mesmo gênero. Por outro lado, o gênero cão possui características acidentais que possibilitam a formação de hierarquias por divisão metafísica, tais como: por comprimento do pelo (cão de pelo curto, cão de pelo longo), por porte (cão de porte pequeno, cão de porte médio, cão de grande porte), dentre outras. Cabe destacar que tanto o gênero como a espécie abarcam todos os indivíduos em todas as épocas e locais que se tenha conhecimento, o que é diferente de um agregado, que pode ser um "grupo particular de indivíduos que pode ou não ter a mesma essência ou natureza de classe; mas, em todo caso, não abarca todos os membros que têm aquela natureza" (JOSEPH, 2008, p. 44). Além disso, a determinação dos gêneros e suas espécies dependem de uma conceituação compartilhada, a qual fornece elementos para que se estipule a identidade dos entes considerados no âmbito de um domínio.

\subsection{DEFINIÇÃO DOS CONCEITOS COM BASE EM SUA IDENTIDADE E SUA INFLUÊNCIA NAS ONTOLOGIAS}

Identidade diz respeito a características que permitem diferenciar indivíduos uns dos outros e identificá-los ao longo do tempo. Por exemplo, uma pessoa pode perder uma orelha (como ocorreu com Van Gogh), e ainda assim continua sendo uma pessoa. Identidade, de acordo com Carrara e Vermaas (2009), fornece um princípio para distinguir e contar objetos de um determinado tipo, permitindo identificar "o que é" tal objeto. Além disso, delimitam o que são objetos de tal tipo em termos de sua essência.

Esta questão leva à noção de propriedade essencial. Lowe (2002) cita duas noções distintas, embora semelhantes, do que é uma propriedade essencial: (i) é aquela que um objeto 
sempre possuiu ao longo de toda a sua existência, e que não pode deixar de possuir sem deixar de existir; (ii) é aquela que um objeto sempre possuiu ao longo de sua existência e que o objeto possui em todo mundo possível ${ }^{18}$ que ele existir.

Cabe ressaltar que quando se trabalha com a noção de mundos possíveis, conforme Lewis (1986), pode-se admitir mais de um ponto de vista na formulação de conceitos, e que considerando que já não é fácil identificar características essenciais considerando um só mundo possível, essa tarefa pode se complicar ainda mais.

Isso posto, uma vez que tenhamos identificado as características essenciais de um referente, temos o seu significado ou intensãa, e é a definição que o torna explícito. De acordo com Dahlberg (1978a, p. 106) "fazer uma definição equivale a estabelecer uma "equação de sentido" sendo que, de um lado (à esquerda) encontramos aquilo que deve ser definido (o definiendum) e de outro (à direita) aquilo pelo qual alguma coisa é definida (o definiens)". Existem diversas formas de se definir um conceito (PAP, 1964), dependendo do propósito. Um tipo de definição útil para os propósitos de uma ontologia é a definição real. Dahlberg (1978a, p. 106) aponta que "a definição real relaciona-se com o conhecimento do objeto. São mencionadas as características essenciais e também as características acidentais muitas vezes, no definiens", e, ainda "com a ajuda da distinção aristotélica entre gênero próximo e diferença específica é possível estruturar as formas simples e complexas das definições reais”. Exemplo de definição por gênero próximo e diferença específica, também denominada de relação lógica (JOSEPH, 2008) seria, para o conceito de número primo "um número que só pode ser dividido por unidade e por ele mesmo" (PAP, 1964, p. 53, tradução nossa). Esse tipo de definição é também denominado de definição clássica ou aristotélica, onde se ressalta o fato que a definição é válida apenas para as instâncias do tipo sendo definido, não podendo se aplicar a outras instâncias de tipos distintos (SEPP ̈̈LÄ et al., 2016, p. 6, tradução nossa), caracterizando um aspecto de disjunção de significado, e sendo recomendada para definição em ontologias:

Nesse caso, as características expressas por Y e Z são individualmente necessárias e, em conjunto, suficientes para que algo seja um X. Esse tipo de definição, que constitui o caso ideal recomendado, também é chamado de definição por condições necessárias e suficientes.

18 Mundo possível, para Lewis é tomado no sentido de assumir a possibilidade de que as coisas que acontecem no mundo poderiam ter acontecido de outro modo, o que poderia levar a observação de diferentes propriedades nos indivíduos. Por exemplo, no mundo real, Van Gogh mutilou a sua orelha, mas em outro mundo possível, poderia não o ter feito. 
Os autores observam ainda que as características das instâncias do gênero as tornam também instâncias da espécie.

Campos (2010, p. 231), por sua vez, salienta que as definições podem contemplar também aspectos de partição e função do conceito, além da questão do gênero próximo. Segundo a autora:

a definição genérica permite identificar a categoria do conceito, a partitiva, os componentes do conceito definido, e a funcional insere o conceito como elemento integrador no contexto analisado, ou seja, ela permite que se identifique, na definição, a função/finalidade do conceito, dentro da área em questão.

Dessa forma, os aspectos elencados por Campos (2010) acima, se observados em conjunto, podem ser usados como base para formar definições que capturam o significado pretendido para o conceito, pois são úteis para caracterizar sua identidade bem como sua unidade, aspectos importantes para se identificar características necessárias e suficientes de um referente.

Nas ontologias, em especial as usadas para fins de inferência, precisamos utilizar definições que identifiquem as características necessárias e suficientes para determinar o que é o definiendum, de modo a poder distingui-lo de outros (CAMPOS; GOMES, 2018), dessa forma, as definições reais são indicadas. Seppälä e outros (2016, p. 7, tradução nossa) também corroboram essa afirmativa, quando apontam que "idealmente, as ontologias contêm apenas definições clássicas porque sua função linguística é eliminar a ambiguidade dos termos" e, ainda, que "sem as condições necessárias e suficientes, torna-se possível interpretar os termos de uma maneira que não está de acordo com o uso pretendido", sendo que as definições clássicas cumprem também importantes papéis de "classificação de instâncias, verificação de consistência, estruturação taxonômica e a regularização da expressão de fatos" (SEPPÄLÄ et al., 2016, p. 20, tradução nossa).

Embora a definição clássica seja desejável em ontologias, observa-se que ela nem sempre é possível, por exemplo, quando a diferença específica não é conhecida, ou para determinados conceitos de natureza dita transcendental, como veracidade, bondade, dentre outros (JOSEPH, 2008). Além disso, em alguns casos pode não ser possível devido à falta de conhecimento científico, e, nesses casos “ontologias (especialmente ontologias grandes) muitas vezes se limitam apenas à declaração das condições necessárias como ferramenta para a 
desambiguação" (SEPPÄLÄ; RUTTENBERG; SMITH, 2016, p. 46, tradução nossa). Entretanto, mesmo que definições com base em características necessárias e suficientes seja possível, é recomendado que se observem as características de um referente no mundo.

\begin{abstract}
O fornecimento de uma definição na forma de uma declaração das condições necessárias e suficientes é obviamente preferível sempre que possível. No entanto, às vezes só podemos usar definições ostensivas, como por exemplo no caso de um termo como 'SARS', para o qual inicialmente pudemos especificar apenas que se referia a uma síndrome que [...] pacientes individuais compartilhavam em comum. (Observe a maneira como uma definição ostensiva desse tipo aponta para um universal na realidade) (KLEIN; SMITH, 2010, p. 6, tradução nossa).
\end{abstract}

Ao transpor as definições para uma linguagem que permita tratamento computacional, como, por exemplo, a OWL-DL, as sentenças que expressam as características dos conceitos constituem os axiomas na ontologia, sendo que ao se formar uma hierarquia pelo princípio de gênero-espécie tem-se um axioma expresso pela relação de subClassOf (subclasse de), o qual indica uma condição necessária (ser do tipo do conceito pai) para as instâncias do conceito subordinado (SEPPÄLÄ; RUTTHEMBERG; SMITH, 2016). Do ponto de vista do tratamento computacional, os axiomas vão apoiar a inferência com base nas classes das ontologias e a conformidade de pertencimento de indivíduos a uma dada classe. Dessa forma, as definições cumprem um papel fundamental nesses instrumentos.

De posse do pressuposto que as definições por gênero próximo e diferença específica fornecem subsídios importantes para a elaboração de ontologias, passamos, a título de ilustração, a compor definições para alguns dos conceitos chave de nosso exemplo hipotético, de modo a evidenciar como elas podem ajudar na compreensão correta da natureza desses conceitos e sua expressão na hierarquia da ontologia. Espera-se com isso que essa estrutura hierárquica reformulada com base nas definições propostas possa embasar de forma mais precisa as inferências obtidas.

Como ponto de partida, seguimos a orientação de Dahlberg (1978b) e realizamos um conjunto de afirmativas verdadeiras sobre os referentes considerados (cafeteira, coador de café e suporte de coador de café). Seguimos também a orientação de Guarino e Welty (2001) de modo a estabelecer características fornecedoras de identidade dos conceitos. Para tal, como forma de apoio, buscamos na literatura ${ }^{19}$ definições para esses conceitos e outros relacionados,

19 Porto Editora - Dicionário infopédia da Língua Portuguesa [em linha]. Porto: Porto Editora. Disponível em https://www.infopedia.pt/dicionarios/lingua-portuguesa/ 
de modo a compor as afirmativas e obter como resultado uma definição adequada. Cabe destacar que como nosso propósito é apenas ilustrativo, não buscamos estabelecer com extremo rigor as definições propostas. Além disso, para fins de simplificar o entendimento, consideramos apenas a natureza básica e a serventia para delimitar as características essenciais dos conceitos, sem nos atermos às suas partes constituintes, uma vez que esses aspectos são suficientes para atender nossos objetivos. O Quadro 2 resume as definições obtidas.

Quadro 2: Conceitos básicos do exemplo proposto e suas definições

\begin{tabular}{|c|c|c|}
\hline Termo & $\begin{array}{l}\text { Característica } \\
\text { essencial }\end{array}$ & Definição \\
\hline Cafeteira & $\begin{array}{l}\text { máquina usada para } \\
\text { fazer café. }\end{array}$ & $\begin{array}{l}\text { Máquina usada } \\
\text { para fazer o café, } \\
\text { podendo ser } \\
\text { elétrica ou não. }\end{array}$ \\
\hline Coador de café & $\begin{array}{l}\text { utensílio usado } \\
\text { para separar } \\
\text { líquidos dos sólidos } \\
\text { contidos nesses } \\
\text { líquidos. }\end{array}$ & $\begin{array}{l}\text { Coador em forma } \\
\text { de saco } \\
\text { semipermeável por } \\
\text { onde passa o café a } \\
\text { ser coado. }\end{array}$ \\
\hline $\begin{array}{l}\text { Suporte de coador } \\
\text { de café }\end{array}$ & $\begin{array}{l}\text { utensílio usado } \\
\text { para apoiar o } \\
\text { coador de café. }\end{array}$ & $\begin{array}{l}\text { Suporte afunilado } \\
\text { de boca redonda, } \\
\text { sem pé, onde se } \\
\text { encaixa o coador } \\
\text { de café. }\end{array}$ \\
\hline
\end{tabular}

Fonte: elaboração da autora.

Nas definições apresentadas do Quadro 2, ainda, de acordo com pesquisa realizada na literatura, considera-se que: (i) um utensílio é um instrumento que serve para executar uma tarefa; (ii) uma máquina é um equipamento composto de peças que automatiza uma tarefa por meio da transformação de algum tipo de energia em outra. Dessa forma considera-se que o que diferencia um utensílio de uma máquina é que um utensílio não automatiza uma tarefa (algum tipo de procedimento manual é esperado), enquanto uma máquina sim. A Figura 5 ilustra a ontologia revisada com base nas definições apresentadas. 
Figura 5: Ontologia de exemplo, com inferência, após reformulação da hierarquia

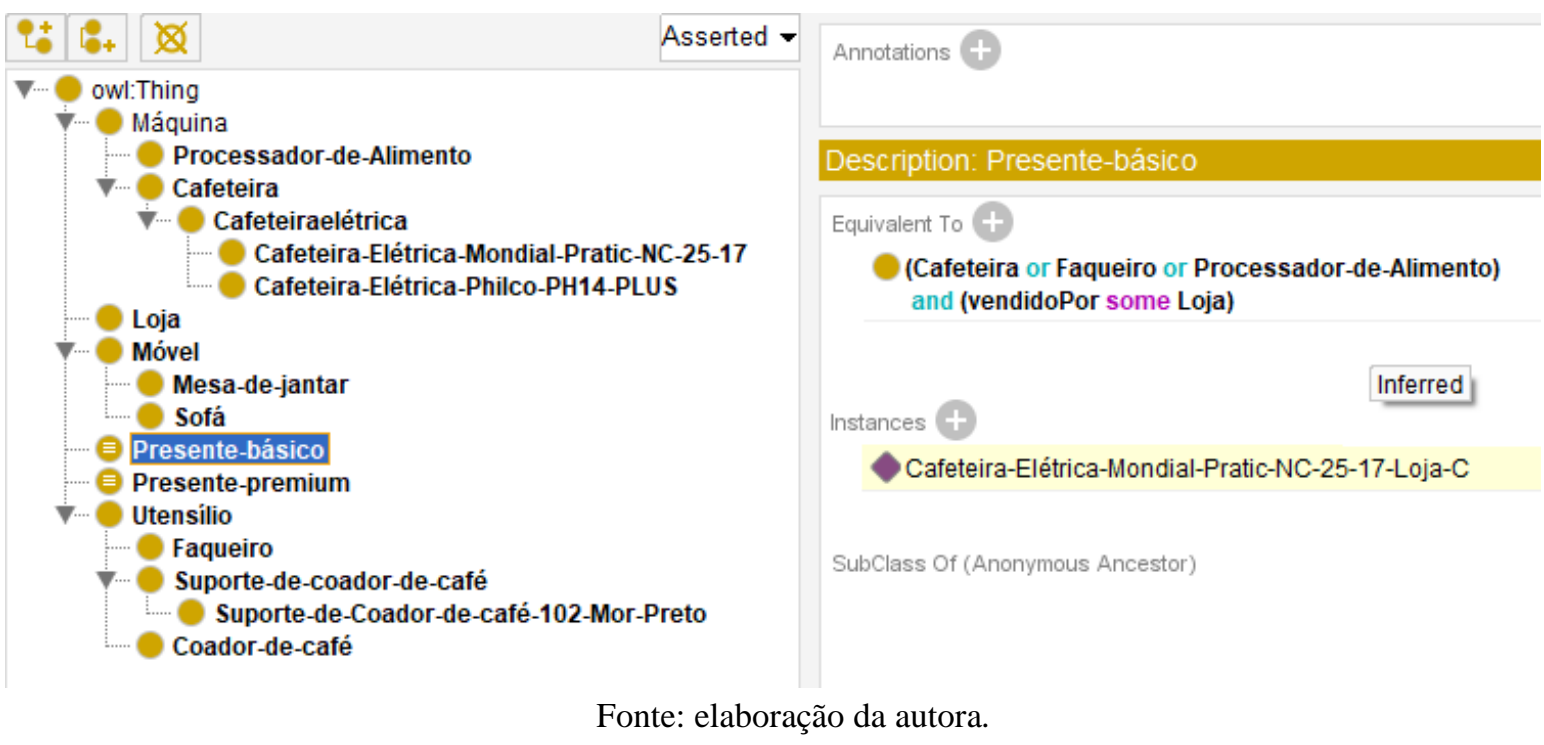

Conforme podemos perceber, o reasoner agora infere corretamente que, de acordo com as opções disponíveis na base de conhecimento, o presente básico a ser sugerido é uma cafeteira elétrica, e não aponta mais como opção possível um coador de café ou um suporte de coador de café. O que parece claro agora, tanto para o ser humano quanto para a máquina, pois são coisas com características essenciais distintas, de diferentes naturezas, não importando se seus nomes são semelhantes de alguma forma (lembrando, de algum modo o preparo do café). Dessa forma, para o ser humano pode fazer algum sentido agrupar o suporte de coador de café, o coador de café e a cafeteira, uma vez que eles formam um agregado, ou uma rede léxica (grafos formados por palavras). Porém, para a máquina, agregados, como vimos anteriormente, não são necessariamente coisas de mesma natureza, o que para a máquina faz toda a diferença, e pode levar a conclusões equivocadas.

\section{CONCLUSÕES}

Objetos informacionais podem ser organizados por diversos princípios, de acordo com sua natureza e com o propósito que se almeja atingir com sua recuperação. Livros são organizados fisicamente em prateleiras em estantes, e para isso instrumentos classificatórios que privilegiem o assunto são adequados para este fim. Por outro lado, os objetos informacionais hoje encontram-se fora dos limites físicos de estantes e prateleiras, são de natureza diversa, atingindo públicos e objetivos informacionais que muitas vezes são difíceis 
de antecipar. $\mathrm{O}$ assunto ou a ordem funcional em determinados casos não vai dar conta das necessidades dos usuários, e instrumentos semânticos estão disponíveis para buscas mais flexíveis e inteligentes, desde que os recursos informacionais sejam descritos de forma adequada, em consonância com requisitos demandados pela tecnologia. Para isso, é preciso que esta seja pensada com base em aportes teóricos que apoiem a elaboração de linguagens que forneçam a semântica necessária para que inferências sejam feitas de maneira coerente e precisa, refletindo de forma mais próxima o entendimento esperado pelo ser humano de uma conceituação lógica da realidade. Hierarquias formadas por princípios pragmáticos que agregam coisas de natureza distinta, muitas vezes levando em conta o nome dos termos, não são adequadas para a obtenção de inferências, pois podem levar a raciocínios equivocados, conforme ilustrou-se nos exemplos apresentados. É preciso levar em conta a identidade das entidades da ontologia, procurando-se sempre que possível definir suas características essenciais. Para isso, a Teoria do Conceito, de Ingetraut Dahlberg traz contribuições relevantes, na medida que parte da definição dos referentes no mundo para determinar suas características essenciais, fornecendo princípios para definições reais, que levam em conta tais aspectos.

\section{REFERÊNCIAS}

BARDIN, L. Análise de conteúdo. São Paulo: Edições 70, 2016.

BITI - Biblioteconomia, Informação e Tecnologia da Informação. Elaboração de tesauros documentários: tutorial. Disponível em: http://www.conexaorio.com/biti. Acesso em: 4 out. 2021.

BRACHMAN, R.; LEVESQUE, H. Knowledge Representation and Reasoning. Morgan Kaufmann, San Francisco, California, USA, 2004.

BRASCHER, M.; CAFÉ, L. Organização da Informação ou Organização do Conhecimento. In: ENCONTRO NACIONAL DE PESQUISA EM CIÊNCIA DA INFORMAÇÃO, 9., 2008, São Paulo. Anais [...]. São Paulo: USP, 2008.

CAMPOS, L. M. Diretrizes para definição de recorte de domínio no reuso de ontologias biomédicas: uma abordagem interdisciplinar baseada na análise do compromisso ontológico. 2011. Tese (Doutorado em Ciência da Informação) - Universidade Federal Fluminense, Niterói, 2011. 
CAMPOS, L. M. Ontologia para o relato de experimentos em um domínio científico: questões e aplicações. In: ENCONTRO NACIONAL DE PESQUISA EM CIÊNCIA DA INFORMAÇÃO, 16., 2015, João Pessoa. Anais [...]. João Pessoa: UFPB, 2015.

CAMPOS, L. M.; CAMPOS, M. L. de A.; CAMPOS, M. L. M. Ranganathans Canons applied to ontology engineering: a sample application scenario in biomedical ontologies. In:

SEMINÁRIO DE PESQUISA EM ONTOLOGIA NO BRASIL (ONTOBRAS), 4., 2011, Gramado. Anais [...]. Gramado: UFRGS, 2011.

CAMPOS, M. L. A; GOMES, H. E. Princípios para modelagem de domínio: a posição de Barry Smith e de Ingetraut Dahlberg. Ciência da Informação, Brasília, DF, v. 41 n. 1, p. 81 94, 2014.

CAMPOS, M. L. A; GOMES, H. E. Ontology: Several Theories on the Representation of Knowledge Domains. Knowledge Organization, [S. l.], v. 44, n. 3, 2017.

CAMPOS, M. L. A; GOMES, H. E. The Onomasiological approach and the function of definitions in the elaboration of domain models in ontologies. In: INTERNATIONAL ISKO CONFERENCE, 15., 2018, Porto, Portugal. Proceedings [...]. Porto, Portugal, 2018. p. 363 370.

CAMPOS, M. L. A. Modelização de domínios de conhecimento: uma investigação de princípios fundamentais. Ciência da Informação, Brasília, v. 33, n. 1, abr. 2004.

CAMPOS, M. L. A. O papel das definições na pesquisa em ontologia. Perspectivas em Ciência da Informação, Belo Horizonte, v. 15, n. 1, 2010.

CARRARA, M.; VERMAAS, P. E. The fine-grained metaphysics of artifactual and biological functional kinds. Synthese, [S. l.], n. 169, p. 125-143, 2009.

DAHLBERG, I. Knowledge organization and terminology: Philosophical and linguistic bases. International Classification, [S. l.], v. 19, n. 2, p. 65-71, 1992.

DAHLBERG, I. Knowledge Organization: A New Science? Knowledge Organization, [ $S$. l.], v. 33, n. 1, 2006.

DAHLBERG, I. Ontical structures and universal classification. Bangalore: Sarada Ranganathan Endowment for Library Science, 1978c.

DAHLBERG, I. A referent-oriented, analytical concept theory of Interconcept. International Classification, [S. l.], v. 5, n. 3, p. 122-151, 1978b. 
DAHLBERG, I. Teoria do conceito. Ciência da Informação, Rio de Janeiro, v. 7, n. 2, p. 101-107, 1978a.

DEBELLIS, M. A Practical Guide to Building OWL Ontologies Using Protégé 5.5 and Plugins. Oxford: University of Manchester, 2021. Disponível em:

https://www.researchgate.net/publication/351037551_A_Practical_Guide_to_Building_OWL _Ontologies_Using_Protege_55_and_Plugins. Acesso em: 6 out. 2021.

DUTTA, B.; DEBELLIS, M. CODO: an ontology for collection and analysis of COVID-19 data. In: INTERNATIONAL JOINT CONFERENCE ON KNOWLEDGE DISCOVERY, KNOWLEDGE ENGINEERING AND KNOWLEDGE MANAGEMENT, 12., 2020.

Proceedings [...]. Budapest, Hungary, 2020. p. 76-85.

FERREZ, H. D. Tesauro de objetos do patrimônio cultural nos museus brasileiros. Rio de Janeiro: Prefeitura do Rio, Secretaria Municipal da Cultura. Produção Fazer Arte, 2016. Disponível em: http://tesauromuseus.com.br/download/tesauro.pdf. Acesso em: 6 out. 2021.

GANGEMI, A.; GUARINO, N.; MASOLO, C.; OLTRAMARI, A.; SCHNEIDER, L. Sweetening ontologies with Dolce. In: KNOWLEDGE ENGINEERING AND KNOWLEDGE MANAGEMENT: ONTOLOGIES AND THE SEMANTIC WEB, 13., 2002, Sigüenza, Espanha. Proceedings [...]. Berlin: Springer, 2002. p. 166-181.

GÖDERT, W.; HUBRICH, J.; NAGELSCHMIDT, M. Semantic Knowledge

Representation for Information Retrieval. Berlin: De Gruyter Saur, 2014.

GOMES, H. E. Manual de elaboração de tesauros monolíngues. Brasília: CNPq/PNBU, 1990.

GOMES, H. E. Taxonomia e a web, construção e uso. [S. l.: s. $n$.], 2014. Disponível em: http://www.conexaorio.com/biti/taxonomianaweb.pdf. Acesso em: 4 out. 2021.

GUARINO, N. The Role of Identity Conditions in Ontology Design. In: INTERNATIONAL JOINT CONFERENCE ON ARTIFICIAL INTELLIGENCE, 16., 1999, Stockholm.

Proceedings [...]. Stockholm, Sweden: IJCAI, 1999. v. 2, p. 2-7.

GUARINO N.; WELTY C. Identity and Subsumption. Padova, Itália: LADSEB CNR, 2001. LADSEB CNR internal report 01/2001. Disponível em: https://citeseerx.ist.psu.edu/viewdoc/download ?doi=10.1.1.101.2288\&rep=rep1\&type=pdf. Acesso em: 6 out. 2021. 
GUARINO, N.; GIARETTA, P. Ontologies and Knowledge Bases. In: MARS, N. J. I. Towards Very Large Knowledge Bases. Amsterdam: IOS Press, 1995.

GUIZZARDI, G. Ontological Foundations for Structural Conceptual Models. Tese (Doutorado em Ciência da Computação) - Universidade de Twente, Enschede, Holanda, 2005.

KLEIN, G.; SMITH, B. Concept Systems and Ontologies: Recommendations for Basic Terminology. Transactions of the Japanese Society for Artificial Intelligence, v. 25. p. 433-441, 2010.

KLEINEBERG, M. The Blind Elephant. A Reply to Claudio Gnoli's Comments. Itália: ISKO, 2014. Disponível em: http://www.iskoi.org/ilc/elephant2.pdf. Acesso em: 8 out. 2021.

JOSEPH, M, Sister. O Trivium: as artes liberais da Lógica, da Gramática e da Retórica. São Paulo: É Realizações, 2008.

KENT, W. Data and Reality: Basic Assumptions in Data Processing Reconsidered. Amsterdam: North-Holland Publishing Company, 1978.

LEWIS, D. On the Plurality of Worlds. Oxford: Blackwell, 1986.

LOWE, E. J. Kinds of Being. A Study of Individuation, Identity and the Logic of Sortal Terms. Oxford: Blackwell, 1989.

LOWE, E. J. A Survey of Metaphysics. Oxford: Oxford University Press, 2002.

LOWE, E. J. More Kinds of Being: A Further Study of Individuation, Identity, and the Logic of Sortal Terms. [S. l.]: John Wiley \& Sons, 2009.

OLIVÉ, A. Conceptual modeling of information systems. [S. l.]: Springer, 2007.

PAP, A. Theory of Definition. Philosophy of Science, Chicago, v. 31, n. 1, p. 49-54, 1964.

RANGANATHAN, S. R. Prolegomena to Library Classification. New York: Asia Publishing House, 1967.

RECTOR, A. et al. OWL pizzas: Practical experience of teaching OWL-DL: Common errors \& common patterns. Lecture Notes in Artificial Intelligence, v. 3257. p. 63-81, 2004. 
REZENDE, A. Curso de Filosofia: para professores e alunos dos cursos do ensino médio e de graduação. Rio de Janeiro: Zahar, 2012.

SANTAREM SEGUNDO, J.; CONEGLIAN, C. Web Semântica e Ontologias: um estudo sobre construção de axiomas e uso de inferências. Informação \& Informação, Londrina, v. 21, n. 2, p. 217-244, maio/ago. 2016.

SCHELLENBERG, T. R. Arquivos modernos: princípios e técnicas. 6. ed. Rio de Janeiro: FGV, 2006.

SEPPÄLÄ, S.; RUTTENBERG, A.; SCHREIBER, Y.; SMITH, B. Definitions in Ontologies. Cahiers de Lexicologie, n. 109, p. 173-205, 2016.

SEPPÄLÄ, S.; RUTTENBERG, A.; SMITH, B. The Functions of Definitions in Ontologies. In: FERRARIO, R.; KUHN, W. (ed.). Formal Ontology in Information Systems:

Proceedings of the Ninth International Conference (FOIS 2016). Amsterdam: IOS Press, 2016. p. 37-50.

SETZER, W. Projeto físico e projeto lógico de bancos de dados. Belo Horizonte: V Escola de Computação, 1986.

SMITH, B.; CEUSTERS, W. Ontological realism: A methodology for coordinated evolution of scientific ontologies. Applied Ontology, v. 5, n. 3-4, p. 139-188, 2010.

SMITH, B.; GRENON, P. The cornucopia of formal-ontological relations. Dialectica, v. 58, n. 3, p. 279-296, 2004.

SMITH B.; KUMAR A.; BITTNER T. Basic Formal Ontology for Bioinformatics. Journal of Information Systems, p. 1-16, 2005.

SMITH, B.; KUSNIERCZYK, W.; SCHOBER, D.; CEUSTERS, W. Towards a Reference Terminology for Ontology Research and Development in the Biomedical Domain. In: CEUR, 2006, Baltimore, MD. Proceedings [...]. Baltimore, MD, 2006. v. 222, p. 57-65.

SPEAR, A. D. Ontology for the Twenty First Century: An Introduction with Recommendations. Saarbrücken, Germany: Institute for Formal Ontology and Medical Information Science, 2006.

STUDER, R.; BENJAMINS, R.; FENSEL, D. Knowledge engineering: Principles and methods. Data \& Knowledge Engineering, v. 25, n. 1-2, p. 161-198, 1998. 
SVENONIUS, E. The Intellectual Foundation of Information Organization. Cambridge, MA: The MIT Press, 2000.

VIEIRA, R. et al. Web Semântica: ontologias, lógicas de descrições e inferências. In: TEIXEIRA, A. C.; BARRÉRE, E.; ABRÃO, I. C. Web e multimídia: desafios e soluções. Belo Horizonte: PUC Minas, 2005. 